\title{
Medical treatment of cystic echinococcosis: systematic review and meta-analysis
}

\author{
Virginia Velasco-Tirado 1,2,3, Montserrat Alonso-Sardón 3,4 Amparo Lopez-Bernus 2,5,6, Ángela Romero-Alegría 2,3,7, \\ Francisco Javier Burguillo ${ }^{8}$, Antonio Muro ${ }^{9}$, Adela Carpio-Pérez ${ }^{2,5,6}$, Juan Luis Muñoz Bellido ${ }^{2,3,10}$, \\ Javier Pardo-Lledias ${ }^{11^{*}}$, Miguel Cordero ${ }^{2,3,12}$ and Moncef Belhassen-García ${ }^{2,3,12^{*}}$ (D)
}

\begin{abstract}
Background: Cystic echinococcosis (CE) is a well-known neglected parasitic disease. However, evidence supporting the four current treatment modalities is inadequate, and treatment options remain controversial. The aim of this work is to analyse the available data to answer clinical questions regarding medical treatment of CE.

Methods: A thorough electronic search of the relevant literature without language restrictions was carried out using PubMed (Medline), Cochrane Central Register of Controlled Trials, BioMed, Database of Abstracts of Reviews of Effects, and Cochrane Plus databases up to February 1, 2017. All descriptive studies reporting an assessment of CE treatment and published in a peer-reviewed journal with available full-text were considered for a qualitative analysis. Randomized controlled trials were included in a quantitative meta-analysis. We used the standard methodological procedures established by the Preferred Reporting Items for Systematic Reviews and Meta-Analyses statement.

Results: We included 33 studies related to the pharmacological treatment of CE in humans. Of these, 22 studies with levels of evidence 2 to 4 were qualitatively analysed, and 11 randomized controlled trials were quantitatively analysed by meta-analysis.

Conclusions: Treatment outcomes are better when surgery or PAIR (Puncture, Aspiration, Injection of protoscolicidal agent and Reaspiration) is combined with benzimidazole drugs given pre- and/or post-operation. Albendazole chemotherapy was found to be the primary pharmacological treatment to consider in the medical management of CE. Nevertheless, combined treatment with albendazole plus praziquantel resulted in higher scolicidal and anti-cyst activity and was more likely to result in cure or improvement relative to albendazole alone.
\end{abstract}

Keywords: Echinococcus granulosus, Cystic echinococcosis, Albendazole, Mebendazole, Praziquantel

\section{Background}

Cystic echinococcosis (CE) is a neglected zoonosis caused by Echinococcus spp., mostly Echinococcus granulosus. Its huge socio-economic impact has been recently recognized. $[1,2]$. CE has a worldwide geographical distribution, and the Mediterranean basin is considered an important endemic area [3]. Four treatment options are currently available: i) surgery, ii) PAIR, iii) chemotherapy with albendazole,

\footnotetext{
* Correspondence: javipard2@hotmail.com; mbelhassen@hotmail.com

${ }^{11}$ Servicio de Medicina Interna, Hospital Marqués de Valdecilla, Avenida Valdecilla 25, 39008 Santander, Cantabria, Spain

${ }^{2}$ Instituto de investigación Biomédica de Salamanca (IBSAL), Universidad de Salamanca, Paseo San Vicente 58-182, 37007 Salamanca, Spain

Full list of author information is available at the end of the article
}

mebendazole or other anthelmintic drugs, and iv) watch and wait for inactive or silent cysts. There is lack of evidence that supports treatment options [4]. This may be because several constraints in health-care system and CE is a chronic, complex disease [5]. Medical treatment is used for reducing cysts, decreasing infectivity and avoiding relapses. Besides, drugs are useful in disseminated or inoperable $\mathrm{CE}$ as the sole modality of treatment. To date, the medical treatment of $\mathrm{CE}$ is based on drugs of the benzimidazole family, usually albendazole $[6,7]$. Over the last few years, praziquantel has been associated with albendazole $[8,9]$. In addition, other drugs like nitazoxanide have also been used in disseminated CE [10]. Despite World Health Organization (WHO) recommendations,

(c) The Author(s). 2018 Open Access This article is distributed under the terms of the Creative Commons Attribution 4.0 International License (http://creativecommons.org/licenses/by/4.0/), which permits unrestricted use, distribution, and 
there is no standard for the medical management of CE, and variability exists in the timing of treatment initiation, dose and duration, which remain undefined.

The aim of this study is to analyse available data to answer the following clinical questions regarding the medical treatment of CE: i) Could pharmacological treatment improve the results of surgical interventions? ii) Is albendazole more effective than mebendazole? iii) Should albendazole be administered alone or in combination with praziquantel?

\section{Methods}

\section{Search strategy and criteria for study selection}

A systematic search of PubMed (Medline), Cochrane Central Register of Controlled Trials (CENTRAL), BioMed, DARE (Database of Abstracts of Reviews of Effects), and Cochrane Plus databases was conducted without language restrictions to identify studies that assessed the efficacy of medical treatment of $\mathrm{CE}$ and had been published up to February 1, 2017.

The following search key words and Boolean operators were entered: ("cystic echinococosis" OR "hydatid disease", OR "Echinococcus granulosus") AND ("medical treatment" OR "albendazole" OR "mebendazole" OR "praziquantel") AND ("randomized controlled trials") AND "humans" [AND NOT "animals"]. Additional records were also identified through other sources (UpToDate) (Additional file 1).

All relevant studies that reported the assessment of one modality of treatment or a comparison of two or several therapeutic methods to treat $\mathrm{CE}$ in humans and were published in a peer-reviewed journal with full text available were considered for analysis and classified according to levels of evidence and grades of recommendation proposed by the Oxford Centre for Evidence-Based Medicine (OCEBM) [11]. Data from editorials, letters to editors, reports of expert committees, and opinions of respected authorities based on clinical experience were excluded from the analysis because these designs do not have the same value, impact or power to make decisions or make recommendations. The results from non-randomized controlled trials, cohort or case-control analytic studies, prospective or retrospective case series, and literature reviews were qualitatively analysed but excluded from our quantitative meta-analysis. We included in the meta-analysis only studies from randomized controlled trials [Level of Evidence 1, Grade of recommendation $\mathrm{A}]$.

\section{Data extraction and quality assessment}

After the relevant studies had been identified and selected, a systematic method was applied to data collection from each included study. The data collected were the first author's name, year of publication, country of origin, study objective, study design, trial time period, number of patients, population characteristics, number of cysts, cyst location, mean cyst size, treatment, endpoint, main quantitative findings and conclusions. All relevant texts, tables and figures were reviewed for data extraction. A quality evaluation of each study was done, and conclusions were based on levels of evidence and grades of recommendation according to OCEBM [11].

The PRISMA (Preferred Reporting Items for Systematic Reviews and Meta-Analyses) statement [12] was used as a guide. Prespecified outcome-specific quality criteria were used to judge the admission of each qualitative and quantitative outcome into the appropriate analysis. Two investigators independently reviewed each eligible study and extracted the information and data necessary to carry out the qualitative analysis and the meta-analysis. Disagreements were resolved by consensus among all authors. The authors evaluated all randomized trials included in the meta-analysis to determine whether they were in accordance with the CONsolidated Standards Of Reporting Trials-CONSORT 2010 statement [12].

\section{Meta-analysis methods}

Meta-analysis was performed utilizing the Cochrane Review Manager (RevMan 5.3) software. Statistical significance was defined at the level of 0.05 . Recommendations of the PRISMA statement were considered as the outcome measure is dichotomic odds ratio was used as effect size. To combine studies to find a summary effect, we have resorted to the Mantel-Haenselz statistical weights. Heterogeneity across studies was followed with the Cochrane Q-statistic (whereby $p \leq 0.05$ was considered statistically significant), and homogenicity of studies was rejected. The $\mathrm{I}^{2}$-statistic was also used to describe the percentage of total heterogenicity across studies. The following suggested cut-off points were used: $\mathrm{I}^{2}=0-25 \%$, no heterogeneity; $\mathrm{I}^{2}=25-50 \%$, moderate heterogeneity; $\mathrm{I}^{2}=50-75 \%$, large heterogeneity; $\mathrm{I}^{2}=75-100 \%$, extreme heterogeneity. A fixed-effect model was used if the $p$-value for $\mathrm{Q}$ was $>0.05$ and $\mathrm{I}^{2}$ was $<50 \%$. However, if both statistics rejected the homogeneity hypothesis, a random-effect model was used. The significance of the pooled odds ratio was evaluated with the $\mathrm{Z}$ test and its two-tailed p-value. Forest plots with odds ratios and their 95\% confidence intervals were used to visualize all results. Unfortunately, the small amount of combinative data published to date did not allow any analysis of publication bias or validation, but the reported values in the present work can be considered consistent.

\section{Results}

Literature search

A PRISMA Flow diagram of the literature search is shown in Fig. 1. 


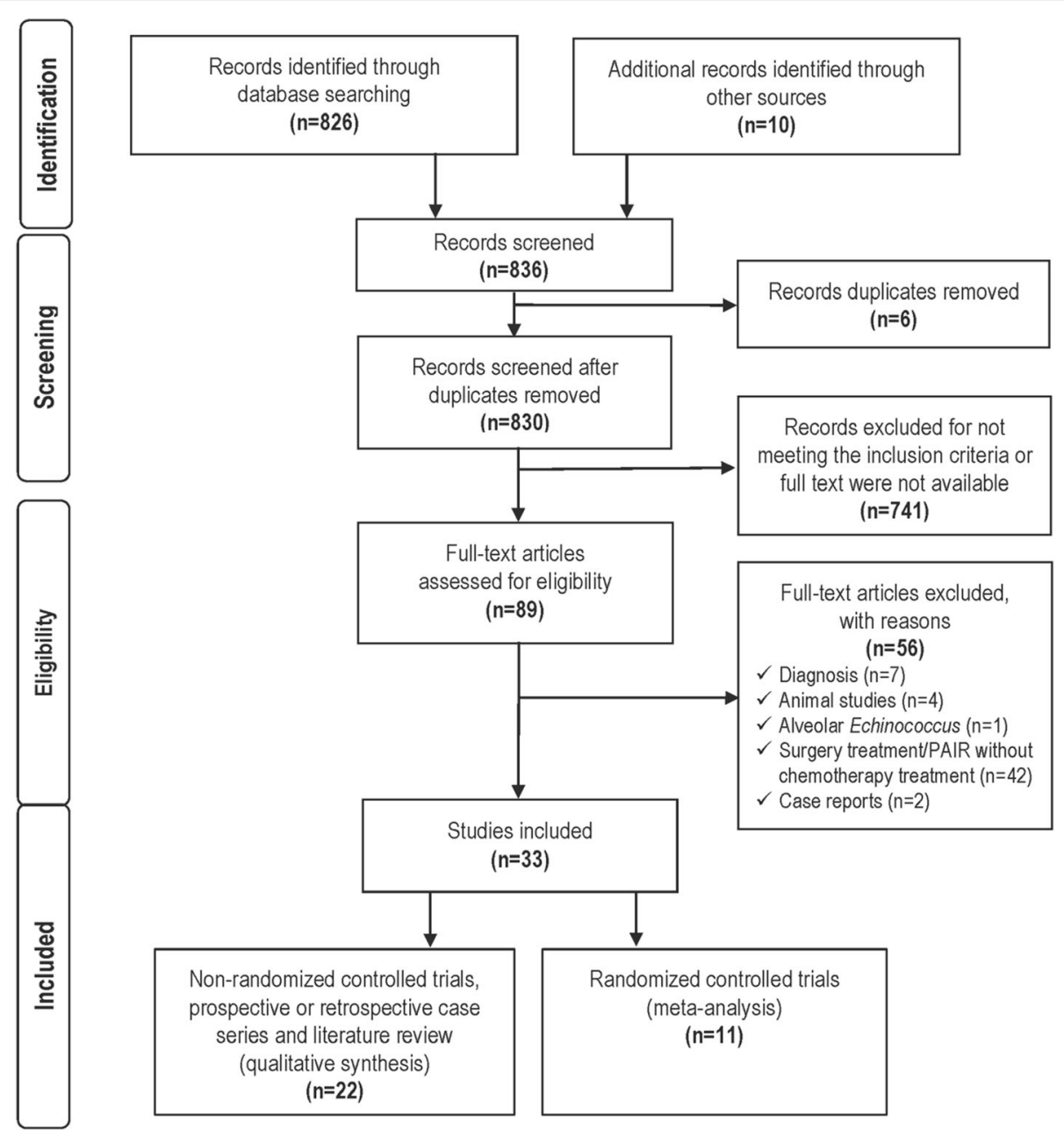

Fig. 1 Flowchart of information through the different phases of the systematic review following the PRISMA recommendations

By searching the electronic database, we identified 826 records related to the medical treatment of $\mathrm{CE}$. Additionally, 10 records were identified through other sources. Six publications were removed because they were duplicate records. We screened 830 records, 741 of them were excluded for not meeting the inclusion criteria or full-text were not available. Eighty-nine full text articles were read in entirety. Fifty-six full-text articles were excluded for reasons including diagnosis (7), animal studies (4), studies of Alveolar echinococcosis (1), surgery treatment and PAIR without chemotherapy (42) and case reports/expert opinion [Level of Evidence 5] (2).

Thirty-three articles $[6,8-10,13-41]$ related to medical treatment of CE in humans that met the inclusion criteria of $\mathrm{CE}$ treatment in humans were selected and classified by type of study design. Of them, 22 studies [6, 10, 13-32] non-randomized controlled trials, prospective or retrospective case series and literature reviews [Levels of Evidence 2 to 4 ] were qualitatively analysed, and 11 randomized controlled trials
[8, 9, 33-41] [Level of Evidence 1] were quantitatively analysed by meta-analysis.

\section{Qualitative synthesis}

This analysis included 22 studies [6, 10, 13-32] with levels of evidence below 1 (2 to 4): non-randomized controlled trial, one paper [13]; cohort study, one paper [21]; prospective descriptive study, six papers [15, 17, 22, 24, 25, 29]; retrospective study, six papers [16, 18, 23, 26, 28, 32]; and case series, two papers $[10,30]$ (Table 1 summarizes the main data of these studies in alphabetical order).

We also included four papers corresponding to literature reviews $[14,20,27,31]$ and two systematic reviews $[6,19]$ in this qualitative analysis (Table 2).

Chronologically, the oldest publication dates back to 1992 from Todorov et al. [29], while the most current was published in 2012 by Ghoshal et al. [18].

The geographic location of studies is varied: England (UK) [14, 19], Germany [6, 20], Italy [15], Spain [10], 


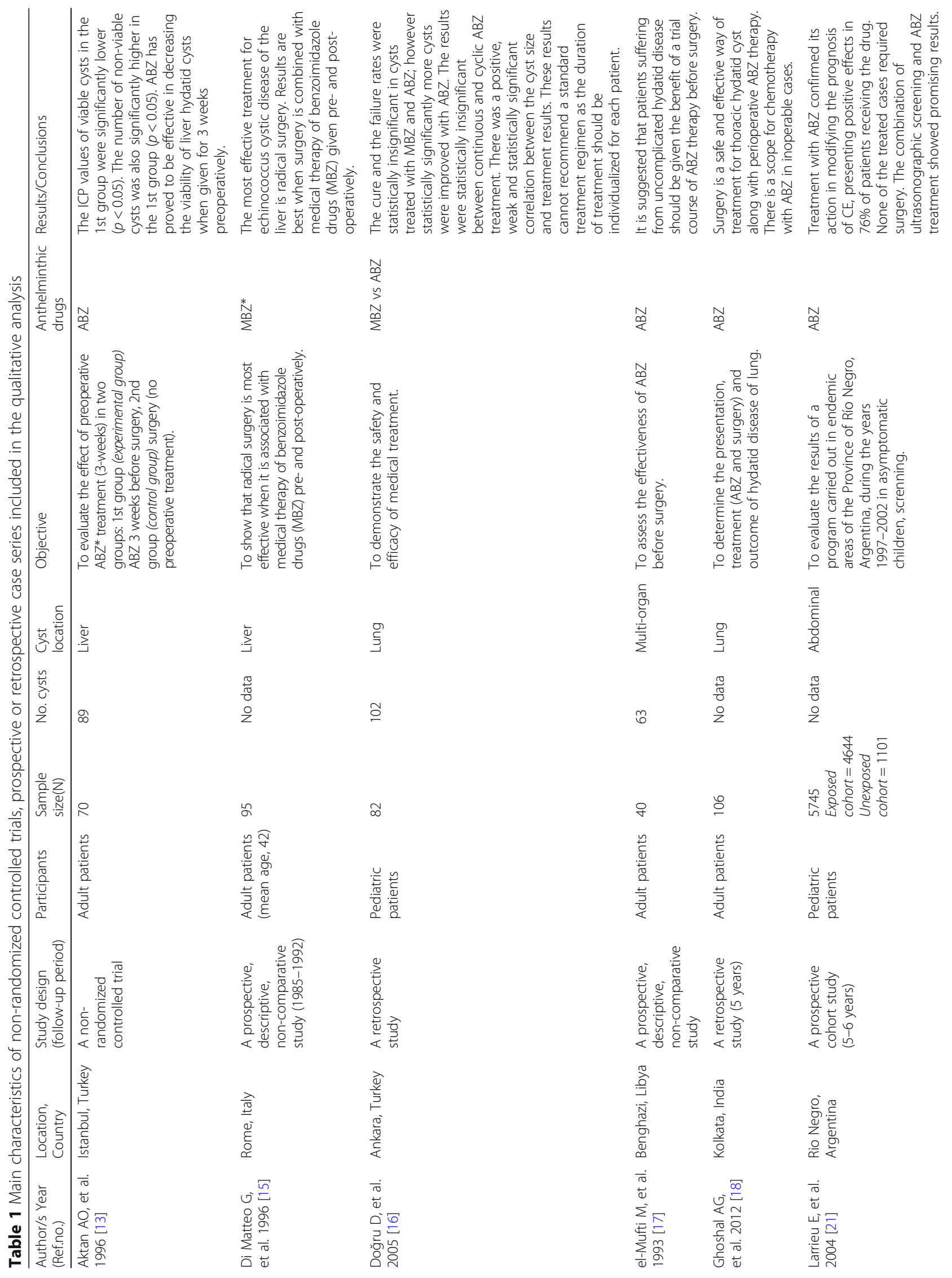




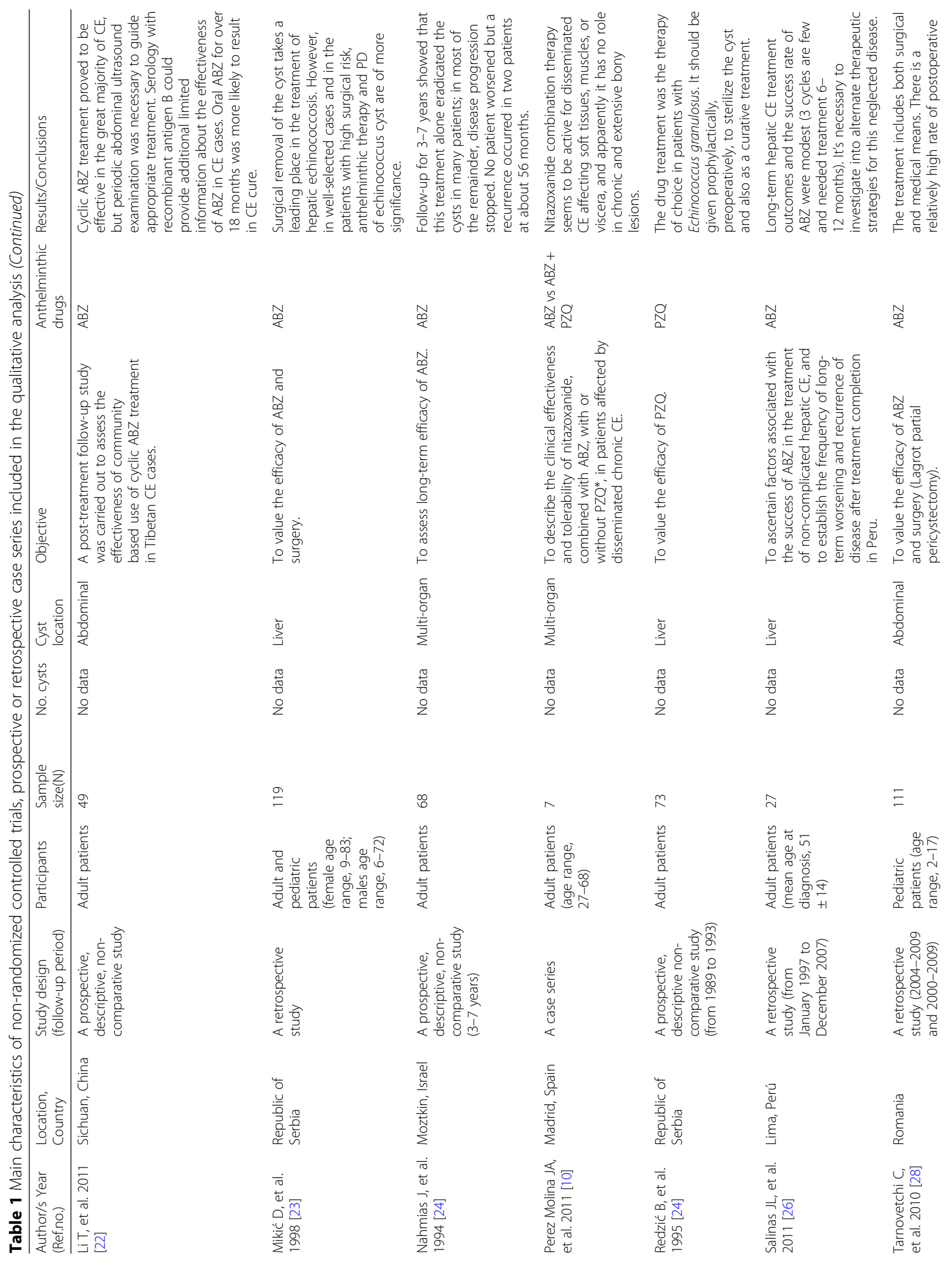




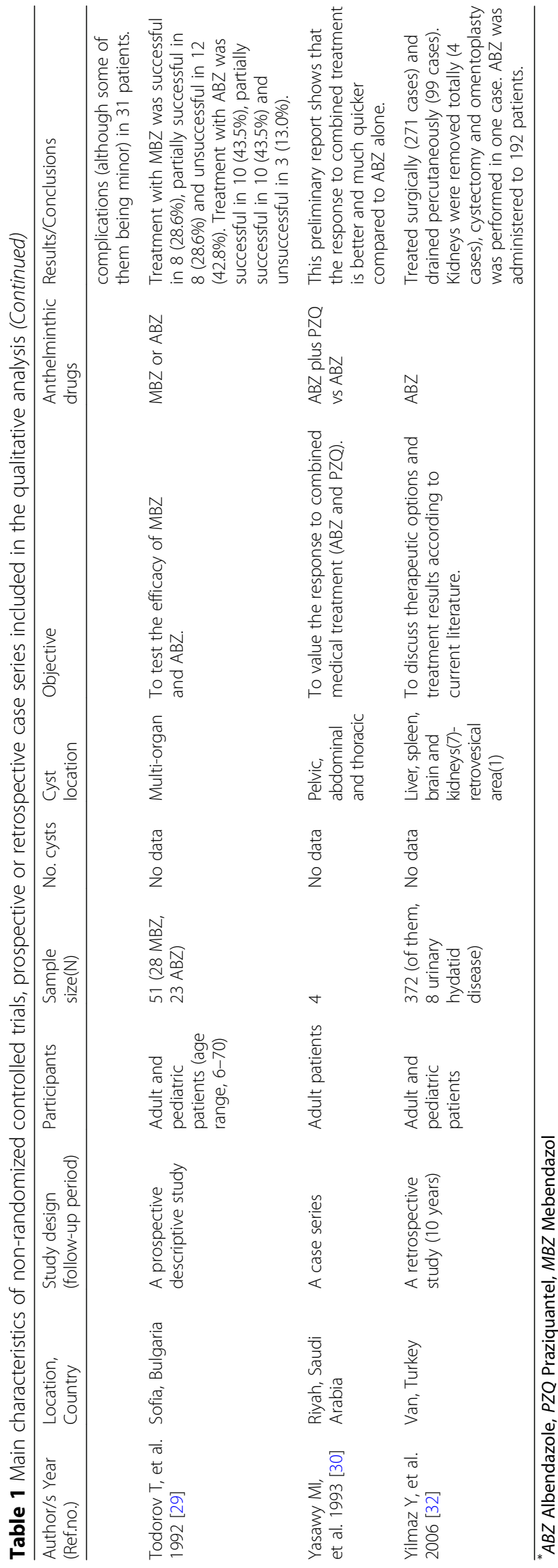




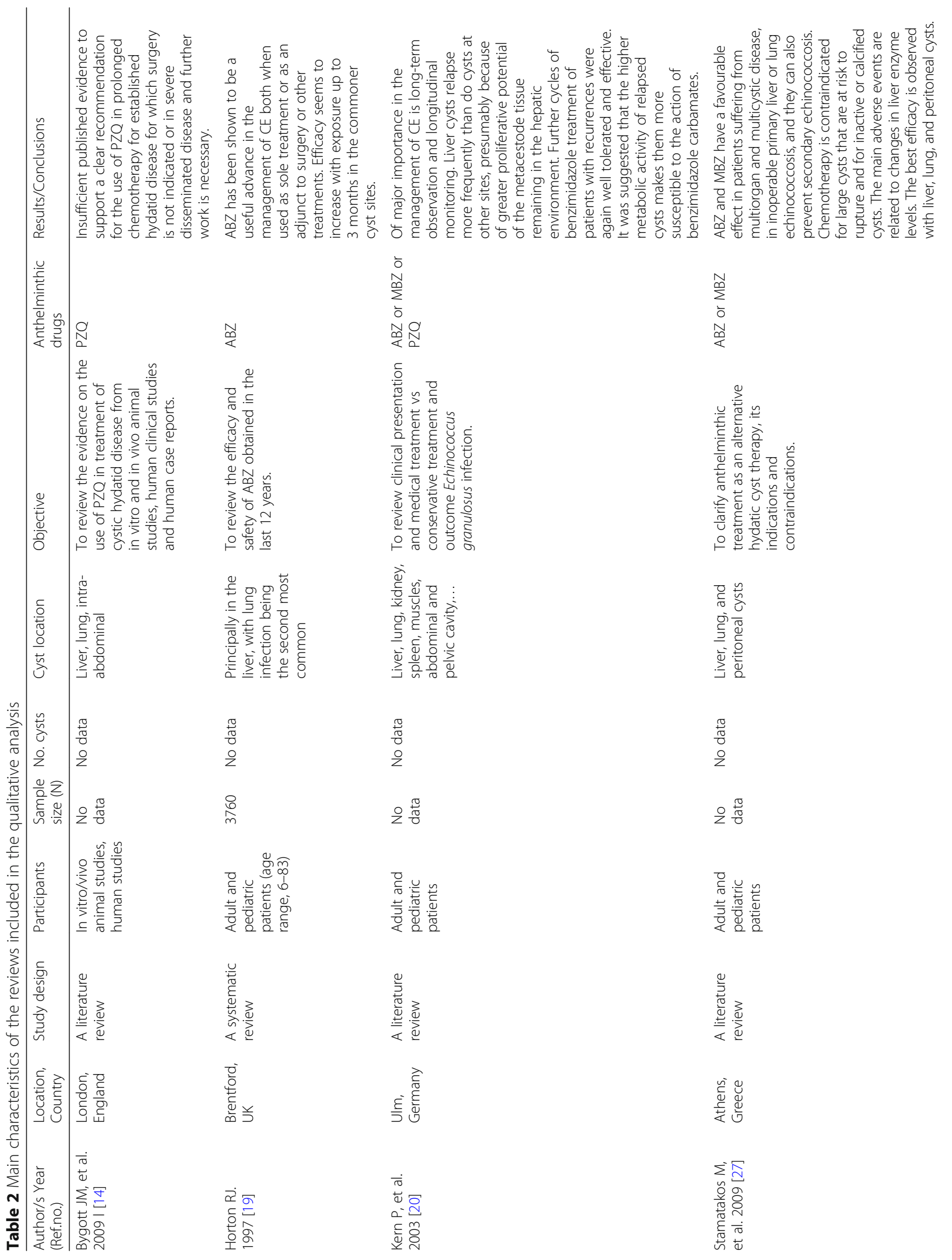




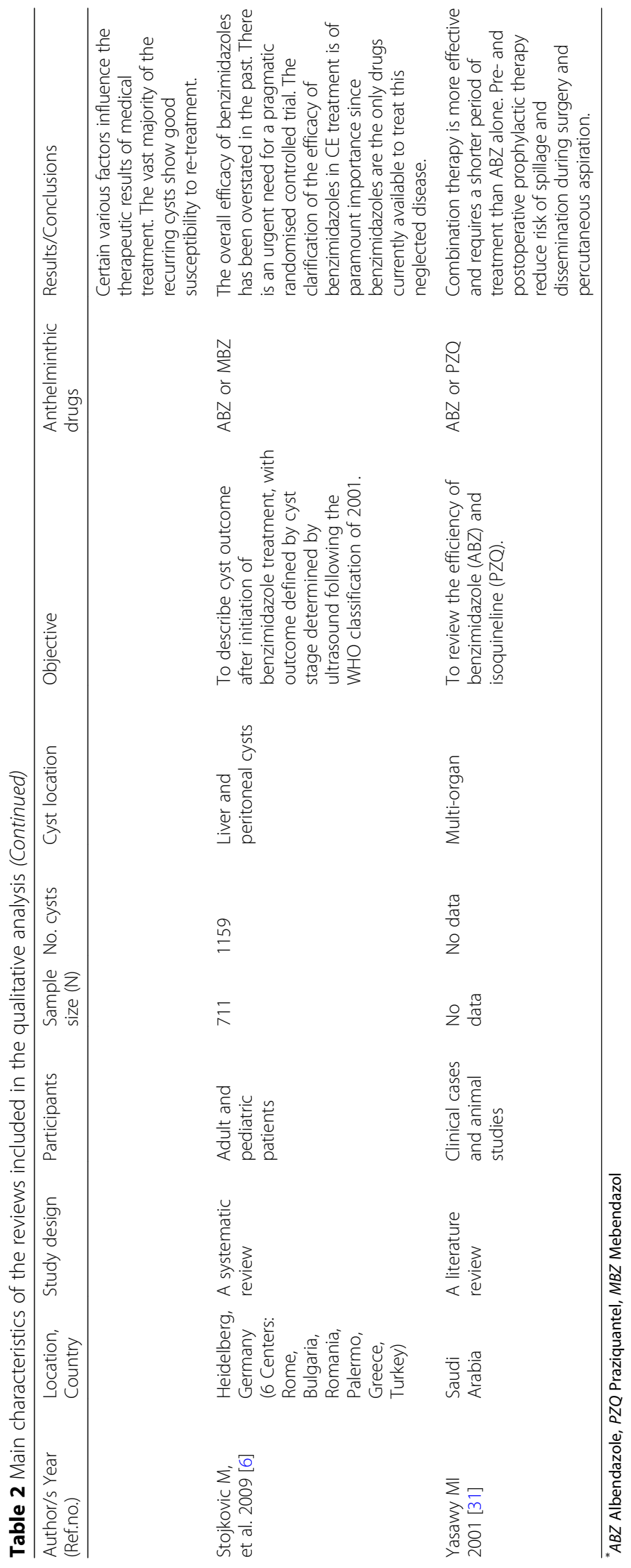


Greece [27], Yugoslavia [23, 25], Romania [28], Bulgaria [29], Turkey [13, 16, 32], Israel [24], Saudi Arabia [30, 31], Libya [17], India [18], China [22], Argentina [21] and Peru [26].

In relation to the study population, ten papers correspond to studies in adult patients $[10,13,15,17,18,22$, 24-26, 30], three papers are studies in pediatric patients $[16,21,28]$, seven studies are in both adults and pediatric patients $[6,19,20,23,27,29,32]$, and two literature reviews covered both animal and human studies [14, 31]. The sample sizes of the studies were very different; 5745 school-age children participated in a study cohort [21], 3760 adult and pediatric patients were included in a systematic review [19], and 7 [10] and 4 [30] adult patients were included in the case series. Other sample sizes were $711,372,119,111,106,95,82,73,70,68,51$, 49,40 and 27 patients.

Relative to cyst location, the studies principally analysed multi-organ/abdominal cysts $[6,10,14,17,19-22,24$, 27-32], liver [13, 15, 23, 25, 26] and lungs [16, 18].

The drug used in most antihelmintic therapies is albendazole $[6,10,13,16-24,26-32]$, alone or combined with mebendazole $[6,15,16,20,27,29]$ or praziquantel $[10,14$, $20,25,30,32]$. All studies are coincident in terms of their results.

From a qualitative assessment of the 22 studies, treatment outcomes are better when surgery or PAIR is combined with pharmacological therapy of benzimidazole drugs given pre- and/or post-operation. Based on a qualitative synthesis, there was a positive and statistically significant association between cyst size and treatment results. More cysts showed statistical improvement with albendazole than with praziquantel or mebendazol. Albendazole combined with mebendazole or praziquantel performed better than albendazole alone.

\section{Quantitative synthesis using meta-analysis}

The meta-analysis included 11 randomized controlled trials [8, 9, 33-41] [Level of Evidence 1, Grade of recommendation A]. The main methodological characteristics of these studies are presented in Table 3, and therapeutic findings are shown in Table 4. Chronologically, the oldest publication dates back to 1986 (Davis et al. [34]), while the most current was published in 2011 (Shams-UI-Bari et al. [41]). The geographic location varies, including Turkey [33], Spain [9, 37], Switzerland [34, 35], Italy [36], Iran [38, 39], India [40, 41] and Saudi Arabia [8].

Most of the participants in the clinical trials were adult patients. The mean age (range age) of the participants was 36.7 (16-64) years in the Shams-UI-Bari et al. [41] study, and the maximum age was $52(4-84)$ in the work of Franchi et al. [36]. The sample size of the studies varies, from 448 patients [36] to 15 [17] [others samples sizes were $121,112,84,72,55,47,41,30$ and 21 patients]. The number of cysts varied from 33 reported by Khuroo et al. [40] to 929 in Franchi et al. [35]. Most of the studies analysed multi-organ/abdominal cyts [8, 34-37, 39], liver [9, $33,40,41]$ and lung [38].

Several studies analysed albendazole alone [33, 37-41] or in combination with mebendazole [34-36] or praziquantel $[8,9]$. Endpoints were protoscolex and cyst viability (viable/ non-viable or intact/dead), and/or response to treatment (cured, improved, no changed, worsened). Due to differences among articles, we could not extract data for statistical treatment from 4 out of 11 papers. In the study by Franchi et al. [35], cysts treated with albendazole relapsed in $134 / 640(20.9 \%)$ cases, while the rate for mebendazole treatment was $37 / 289(12.8 \%)$. In the case series by Keshmiri et al. 1999 [38] and 2001 [39], only one case relapsed following albendazole treatment $(1 / 11 ; 9.1 \%)$, and 1/17 (5.8\%) relapsed following mebendazole treatment. According to Shams-UI-Bari et al. [41], patients who did not receive albendazole therapy reported a recurrence rate of $6 / 36(16.6 \%)$, while no recurrence was reported in patients who received albendazole therapy $(p<0.01)$. Albendazole therapy was associated with fewer recurrences than mebendazole therapy.

Seven studies were examined in three meta-analyses, as described below.

i) Albendazole plus surgery versus surgery alone. Blidik et al. [33], Gil-Grande et al. [37], Khuroo et al. [40], and Shams-UI-Bari et al. [41] address this issue. These studies compare albendazole plus surgery to surgery alone and analyse the viability of the scolex as a common point. In all 3 studies, the number of non-viable scolex in the experimental group (albendazole plus surgery) is higher than the control group (surgery alone) (Tables 3 and 4). These three studies were significantly heterogeneous $(p=0.01$ for $\mathrm{Q}$ test and $78 \%$ for $\mathrm{I}^{2}$ ), so a random-effects model was used. The results are shown as a forest plot in Fig. 2.

The summary odds ratio was 48 , which is clearly significant in favor of albendazole plus surgery, with a $p$-value of 0.002 according to the $\mathrm{Z}$ test. Davis et al. 1986 [34], Davis et al. 1989 [35], Keshmiri et al. 1999 [38] and Keshmiri et al. 2001 [39] answer the second clinical question that we considered in this meta-analysis:

ii) Albendazole versus mebendazole. These studies compare albendazole to mebendazole (Fig. 3) and analyse the response to treatment (cured, improved, no changed, worsened) as a common point. In all studies, the proportion of cysts cured/success or improvement in the experimental group (albendazole) is higher than that in the control group (mebendazole or placebo) (Table 4). 


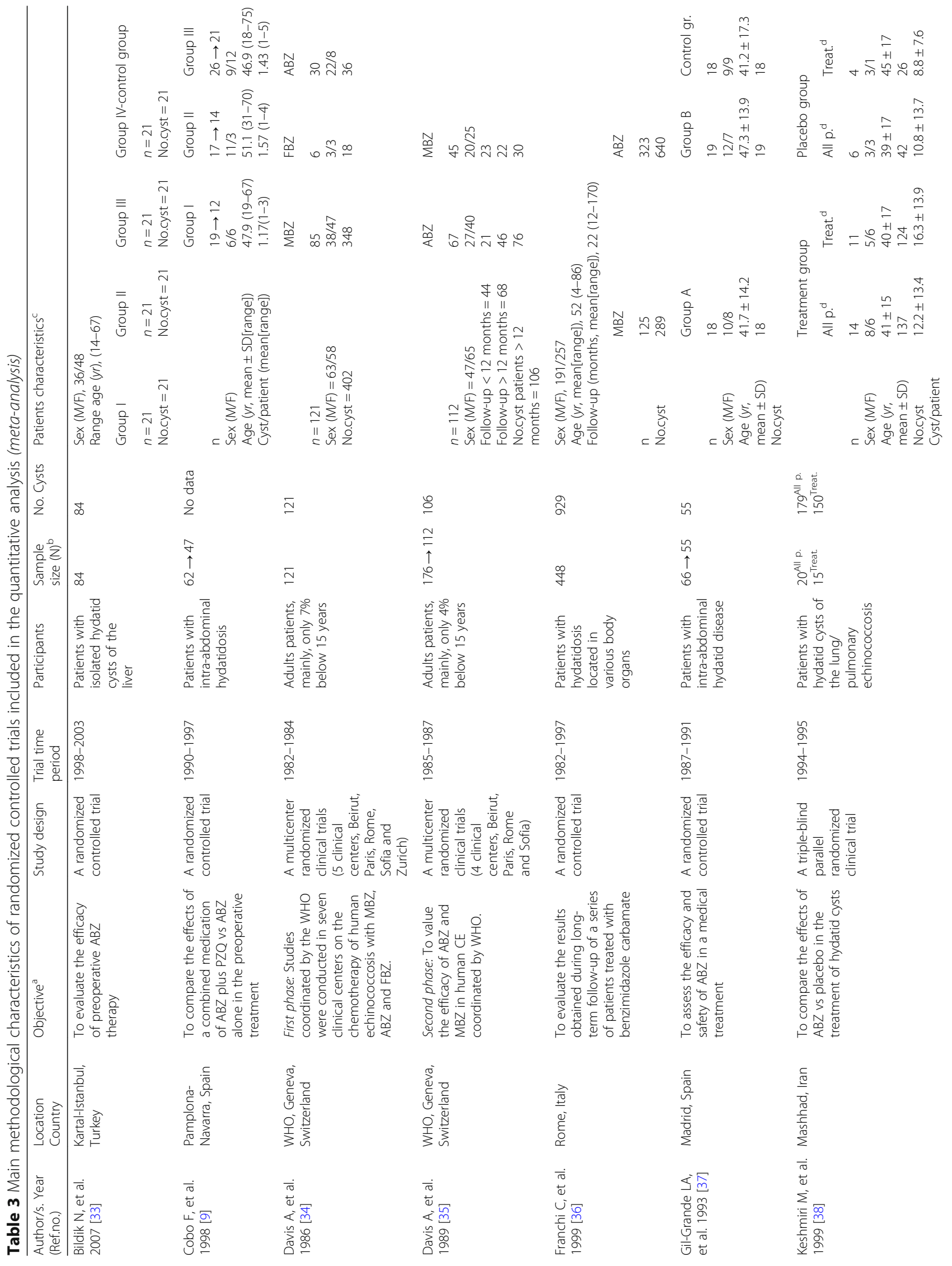




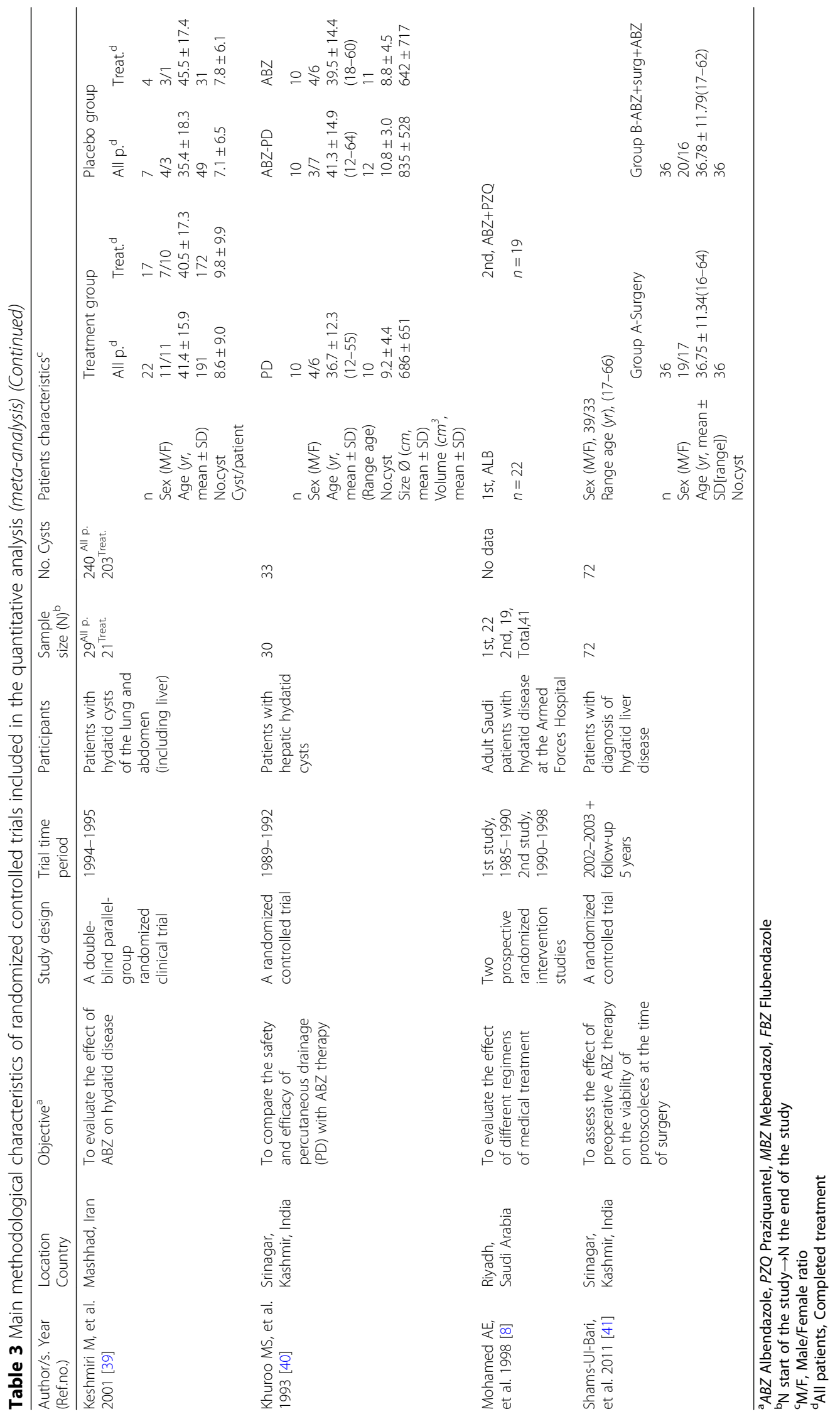




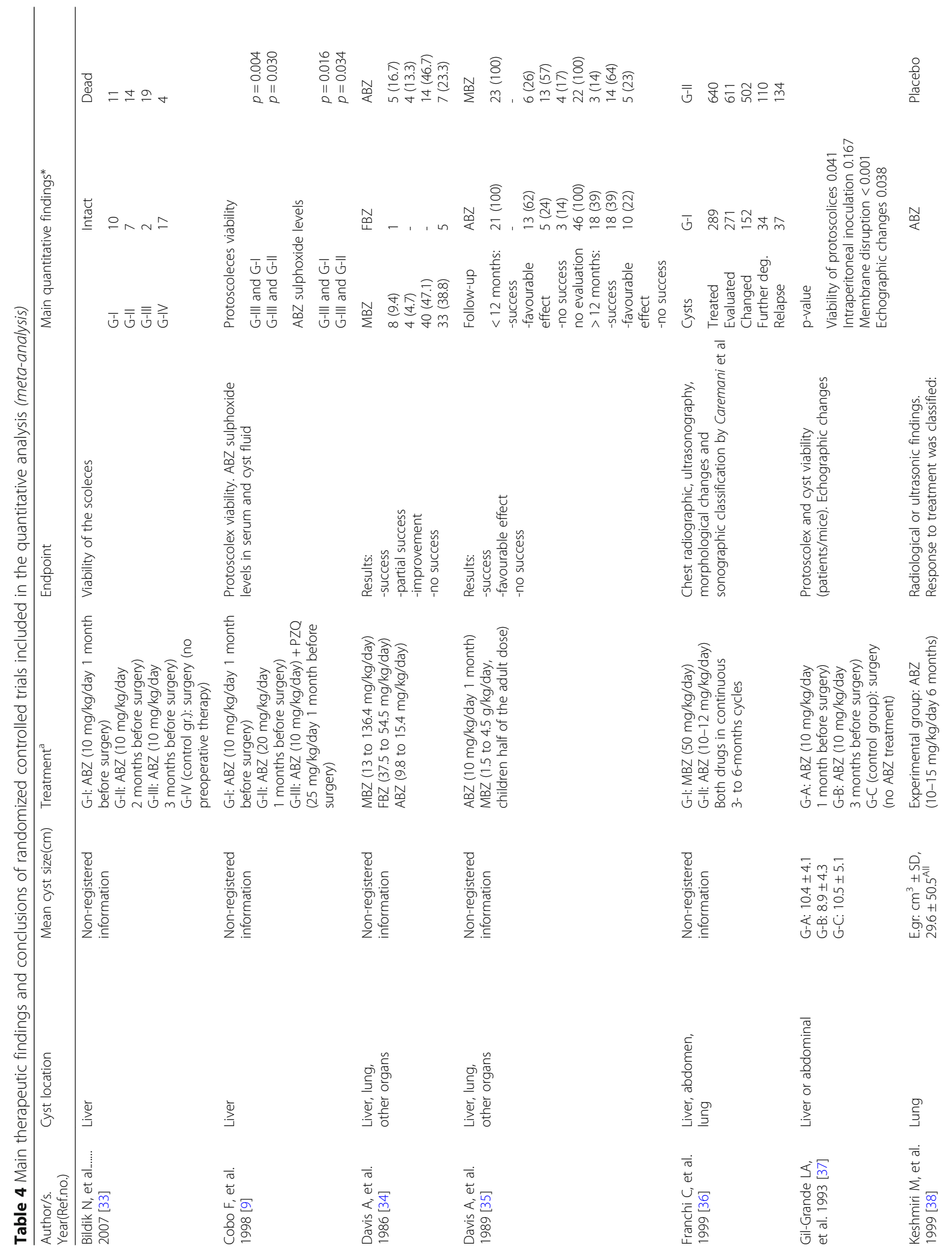




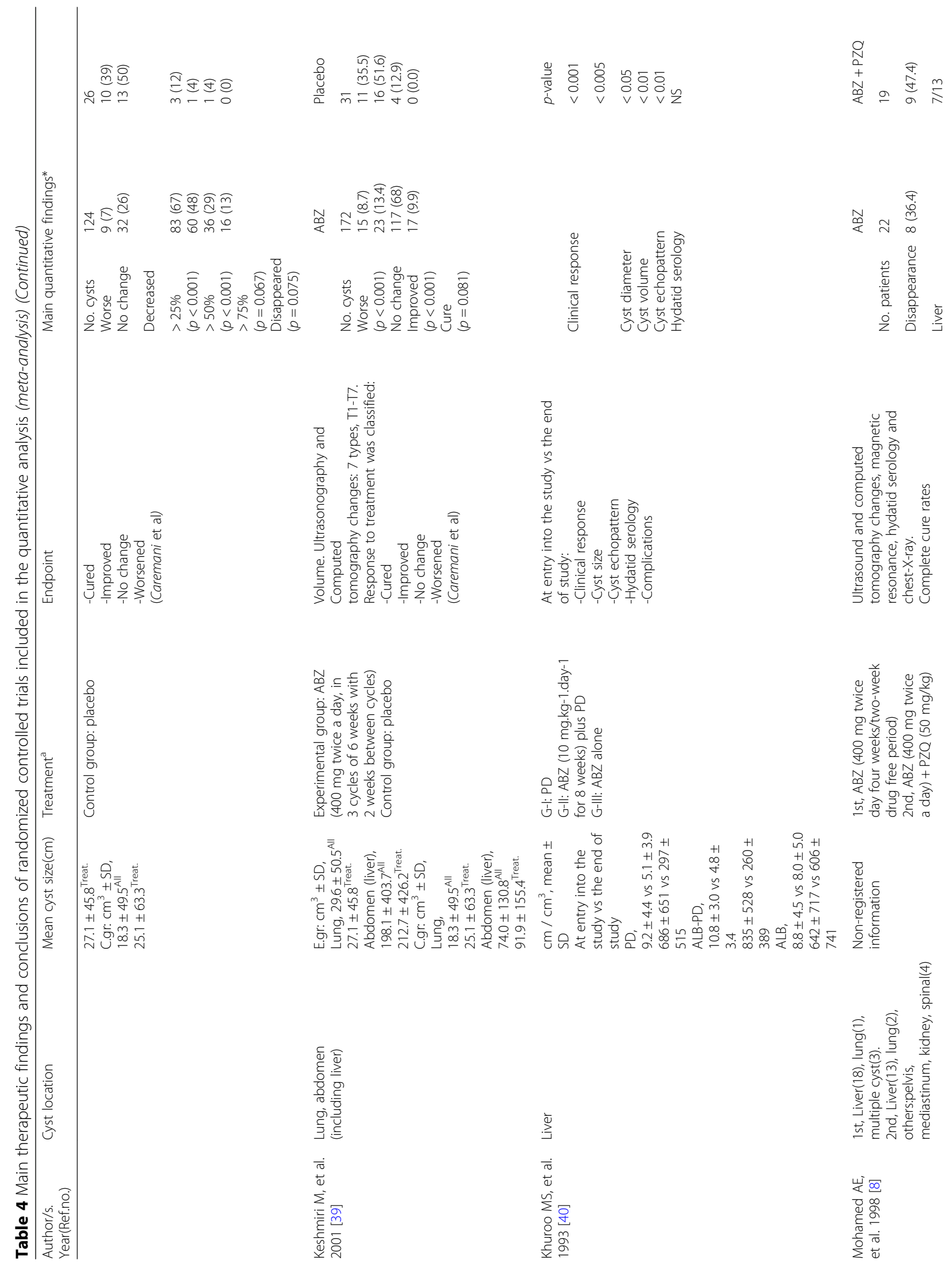




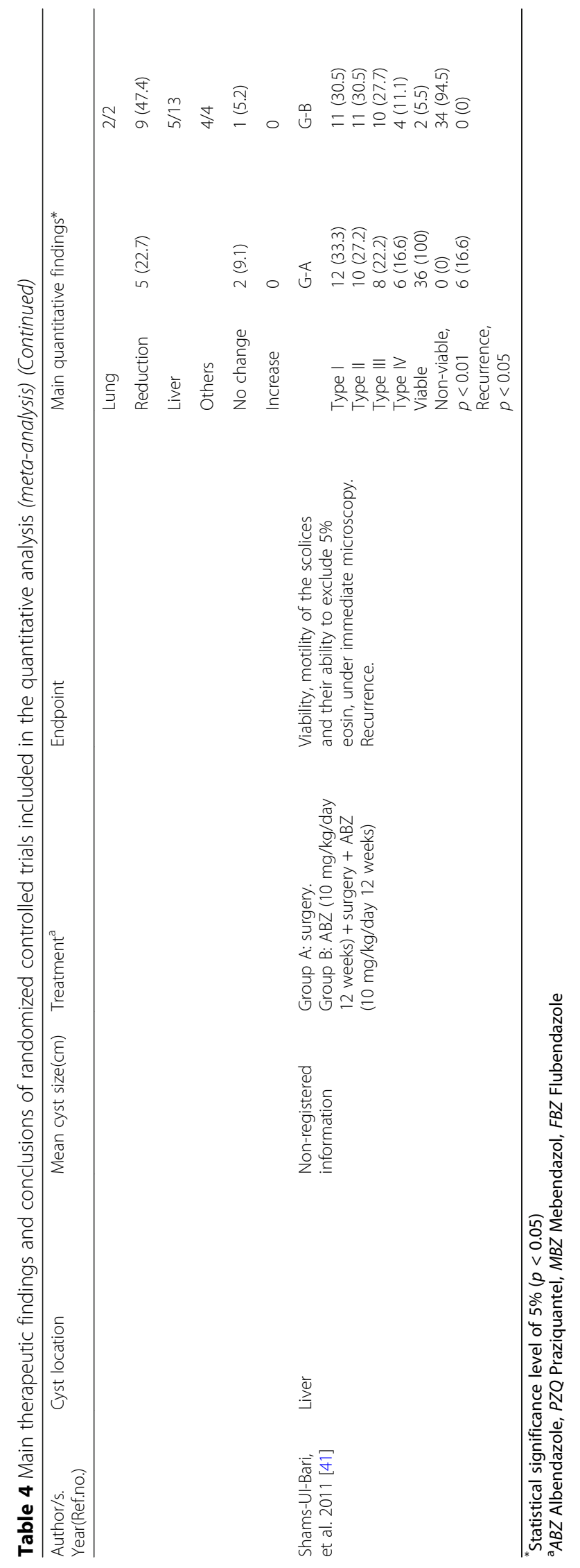




\begin{tabular}{|c|c|c|c|c|c|c|c|c|c|}
\hline \multirow[b]{2}{*}{ Study or Subgroup } & \multicolumn{2}{|c|}{ Experimental } & \multicolumn{2}{|c|}{ Control } & \multirow[b]{2}{*}{ Weight } & \multirow{2}{*}{$\begin{array}{l}\text { Odds Ratio } \\
\text { M-H, Random, } 95 \% \mathrm{Cl}\end{array}$} & \multirow{2}{*}{\multicolumn{3}{|c|}{$\begin{array}{l}\text { Odds Ratio } \\
\text { M-H, Random, } 95 \% \mathrm{Cl}\end{array}$}} \\
\hline & Events & Total & Events & Total & & & & & \\
\hline Bildik (2007) & 19 & 21 & 4 & 21 & $35.8 \%$ & $40.38[6.55,248.97]$ & & $=$ & \\
\hline Gil-Grande (1993) & 16 & 19 & 8 & 18 & $37.7 \%$ & $6.67[1.42,31.23]$ & & - & \\
\hline Shams-UI-Bari (2011) & 34 & 36 & 0 & 36 & $26.5 \%$ & $1007.40[46.68,21740.90]$ & & & $\longrightarrow$ \\
\hline Total $(95 \% \mathrm{Cl})$ & & 76 & & 75 & $100.0 \%$ & $47.97[3.93,586.25]$ & & & \\
\hline Total events & 69 & & 12 & & & & & & \\
\hline \multicolumn{7}{|c|}{$\begin{array}{l}\text { Heterogeneity: } \operatorname{Tau}^{2}=3.70 ; \mathrm{Chi}^{2}=8.98, d f=2(P=0.01) ; I^{2}=78 \% \\
\text { Test for overall effect: } Z=3.03(P=0.002)\end{array}$} & 0.0010 .11 & $\begin{array}{c}10 \\
\text { Favours [control] }\end{array}$ & 1000 \\
\hline \multicolumn{10}{|c|}{$\begin{array}{l}\text { Fig. } 2 \text { Forest plot of comparison: intervention (albendazole plus surgery) vs control (surgery alone), outcome: Viability of scolex (Event = non-viable } \\
\text { or dead) }\end{array}$} \\
\hline
\end{tabular}

Figure 3 (forest plot) shows the results [34, 35]. The $\mathrm{Q}$ test of heterogeneity was not significant $(p=0.73)$, indicating excellent homogeneity $\left(\mathrm{I}^{2}=0 \%\right)$ of these studies.

iii) Albendazole versus placebo. These studies compare albendazole to placebo and analyze the response to treatment (cured, improved, no changed, worsened) as a common point. In both studies, the proportion of radiological cured/success or improvement in the experimental group (albendazole) is higher than that in the control group (placebo). Figure 4 shows the results obtained from comparing albendazole to placebo [38, 39].

The test of heterogeneity was not significant $(p=0.89)$, indicating excellent homogeneity $\left(\mathrm{I}^{2}=0 \%\right)$.

Cobo et al. [9], answer the third clinical question that we considered in this meta-analysis.

iv) Albendazole versus albendazole plus praziquantel. It was not possible to statistically combine the data comparing albendazole plus praziquantel treatment to albendazole alone. However, an answer is given in Mohamed et al. [8] and Cobo et al. [9]. In the latter paper [9], the number of non-viable scoleces in the albendazole plus praziquantel group was higher than in the albendazole alone group. According to Mohamed et al. [8], the reduction in the number of cysts and cases cured or improved in the albendazole plus praziquantel group was higher than it was in albendazole alone group (Table 4). It was not possible to generate a forest plot.

\section{Discussion}

The clinical handling of $\mathrm{CE}$ involves four therapeutic alternatives: surgery, percutaneous intervention, drugs, and the "watch and wait" approach for quiescent cysts. The evidence supporting pharmacological treatment is weak. This lack in quality is due to i) small number of patients forming an homogeneous clinical group, even in referral hospitals in endemic countries; ii) the different applied methodology prevents comparison between studies; iii) $\mathrm{CE}$ is a chronic disease, which requires long-term monitoring to determinate the effectiveness of an intervention [42]. There are no gold standard methods to determinate biological status and response to treatment [37]. Druginduced echographic changes can be compare with viability studies of protoscoleces developed on surgically removed cysts, which would generate parasitological data to correlate with clinical effects. These objectives were used by Gil Grande et al. [37] in their randomized controlled trial of the efficacy of albendazole, but data collection has not been posible for praziquantel, despite its clinical use in last 20 years. Furthermore, hydatid cysts may spontaneously

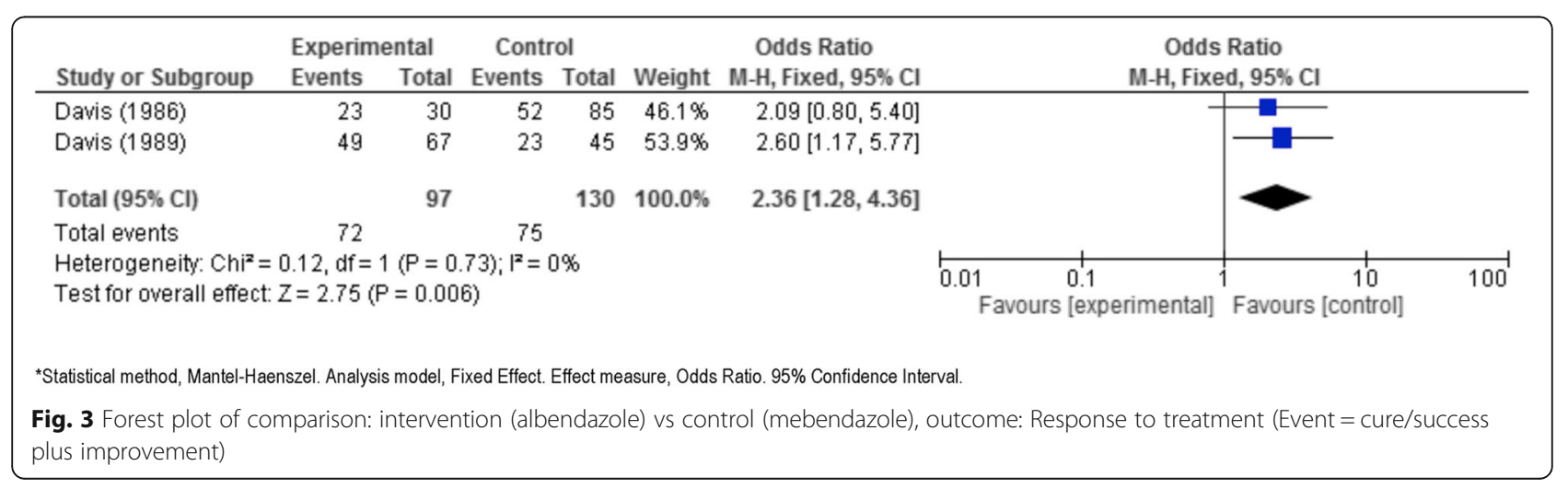




\begin{tabular}{|c|c|c|c|c|c|c|c|c|c|}
\hline \multirow[b]{2}{*}{ Study or Subgroup } & \multicolumn{2}{|c|}{ Experimental } & \multicolumn{2}{|c|}{ Control } & \multirow[b]{2}{*}{ Weight } & \multirow{2}{*}{$\begin{array}{l}\text { Odds Ratio } \\
\text { M-H. Fixed. } 95 \% \text { Cl }\end{array}$} & \multirow{2}{*}{\multicolumn{3}{|c|}{$\begin{array}{l}\text { Odds Ratio } \\
\text { M-H, Fixed, } 95 \% \mathrm{Cl}\end{array}$}} \\
\hline & Events & Total & Events & Total & & & & & \\
\hline Keshmiri (1999) & 10 & 11 & 1 & 4 & $41.2 \%$ & $30.00[1.41,638.15]$ & & & \\
\hline Keshmiri (2001) & 15 & 17 & 1 & 4 & $58.8 \%$ & $22.50[1.51,335.34]$ & & & \\
\hline Total $(95 \% \mathrm{Cl})$ & & 28 & & 8 & $100.0 \%$ & $25.59[3.39,193.22]$ & & & \\
\hline Total events & 25 & & 2 & & & & & & \\
\hline \multicolumn{7}{|c|}{ Heterogeneity: $\mathrm{Chi}^{2}=0.02, \mathrm{df}=1(\mathrm{P}=0.89) ; \mathrm{I}^{2}=0 \%$} & $0.001 \quad 0.1 \quad 1$ & $\begin{array}{c}10 \\
\text { Favours [control] }\end{array}$ & 1000 \\
\hline \multicolumn{10}{|c|}{$\begin{array}{l}\text { Fig. } 4 \text { Forest plot of comparison: intervention (albendazole) vs control (placebo), outcome: Response to treatment (Event = cure/success } \\
\text { plus improvement) }\end{array}$} \\
\hline
\end{tabular}

regress with shedding of membranes, solidifying and calcification in their natural history, without any chemotherapeutic assistance [43].

Despite attempts by the WHO, the management of CE disease remains a major problem [44]. There is no consensus on disease management $[1,45]$. Thereby, studies to establish the efficacy of medical treatment, the dosing and the minimal effective dose have not been yet determined by sufficient evidence. Case definitions, diagnostic proceedings and defined monitoring methods for longterm follow-up need to be standardised, and comparative efficacy surveys need to be performed. Future progress in chemotherapy may be attained by identifying drugs with higher anti-echinococcal activity.

\section{Clinical question 1}

\section{Surgery/PAIR vs surgery/PAIR plus albendazole/ mebendazole}

Our data show that treatment outcomes are better when surgery or PAIR is combined with chemotherapy of benzimidazole drugs given pre- and/or post-surgery. The summary odds ratio found in the meta-analysis shows a value of 48 (95\% CI: 4-586), which is far greater than the value of 1 that would indicate equality of the treatments.

Chemotherapy is applied in many scenarios, so it is very difficult to standardize the results. Anthelmintics are usually indicated before and after surgery to reduce the size of cysts, to sterilise them, and to prevent relapses. Furthermore, medical treatment is the only therapeutic option in scattered $\mathrm{CE}$ and/or inoperable CE. To date, there are insufficient data to establish the optimal duration of treatment or frequency of dose. Recommendations on the timing of the start of chemotherapy before surgery or PAIR are varied. Preoperative treatment with albendazole begins at least 3 months to 1 day before surgery and/or PAIR and continues for 1-3 months post-treatment, and there is no clear recommendation on praziquantel dosage schedules. In terms of cyst viability and radiological efficacy, the data are not conclusive as to whether longer courses of treatment
(3 months) are more efficacious than shorter courses of treatment [19, 37].

The additional benefit from very long treatment (more than 6 months) is marginal for most patients, and although it is performed in clinical practice with patients with multiple or inoperable CE, it has never been well evaluated. There is a suggestion that lesions in organs other than the liver, lung and peritoneum may benefit from more prolonged therapy, but the numbers are small.

\section{Clinical question 2 \\ Albendazole vs. mebendazole}

Our data show in all of the studies that the odds ratio of cure/success or improvement in the albendazole group is greater than those in the other groups (mebendazole or placebo). To be exact, the summary odds ratio for albendazole versus mebendazole was 2.4 (95\% CI: 1.3, 4.4) with a $p$-value of 0.006 . There is some evidence that albendazole should be chosen over mebendazole, at least until more trials are reported. As expected, the comparison of albendazole and placebo is in favor of the drug treatment, with a p-value of 0.002 for the $\mathrm{Z}$ test of significance.

Mebendazole is a broad-spectrum antihelminthic agent of the benzimidazole type with in vivo activity in CE. Nevertheless, albendazole is more active in vitro than mebendazole and has better gastrointestinal uptake and bioavailability [46]. It has been published better clinical outcomes with albendazole [47]. Flubendazole is not already used for hydatidosis. Testing hepatic enzymes and blood count every 2 weeks is recommended during benzimidazole treatment to monitor most frequent adverse effects [48]. Although it is orally administered, albendazole results in high serum concentration but penetration into cyst is patchy. Albendazole and mebendazole may reduce volume of hydatid cysts and may become them sterile in some cases [47]. However, less than half treated patients achieve clinical and radiological resolution without concomitant drainage [47]. Albendazole, with or 
without PAIR, is usually given in two divided doses $(10-15 \mathrm{mg} / \mathrm{kg} /$ day) or $400 \mathrm{mg}$ once a day. Daily dose of mebendazol is $40-50 \mathrm{mg} / \mathrm{kg}$ in three divided doses. Treatment may be administered in several cycles (1-6) separated by 10-14 days. Clinical and radiographic improvement is frequently noticeable. Radiological endpoints are commonly defined as more than $25 \%$ decreases in cyst size, membrane detachment or cyst calcification. Cyst disappearance occurs in less than $50 \%$ of patients in medical treatment [49]. Our data show that the efficacy of albendazole was superior to that of mebendazole, with a $p$-value of 0.009 . Although there are works that show that the rate of relapse was similar for patients treated with albendazole or mebendazole, it is necessary to carry out prospective studies over long periods to generate robust data.

\section{Clinical question 3}

\section{Albendazole vs albendazole plus praziquantel}

Our data show that combined treatment with albendazole plus praziquantel is superior to treatment with albendazole alone.

Praziquantel, an isoquinolone derivative, has had limited use in the treatment of CE [47]. Praziquantel has shown efficacy in vitro and in animal models. Weekly dose of $50 \mathrm{mg} / \mathrm{kg}$ or dose every 2 weeks have displayed suitable pharmacokinetics in humans [47]. There are few clinical studies documenting praziquantel benefits in humans $[8,9,30,50]$; however, combination of praziquantel with mebendazole [50] or albendazole $[8,9]$ seems to be more effective and possibly more rapid than benzimidazole monotherapy. The earliest report of a trial of combination praziquantel and albendazole in the treatment of human hydatid disease was made by Yasawy et al. [30]. Major disadvantages of these works are different praziquantel schemes: various treatment groups are too small for significant analysis and failure to use matching controls $[8,30]$. Combination of praziquantel and albendazole may produce some benefit in pre- and post-intervention chemotherapy and might be helpful when spillage occurs during surgical procedure $[8,9]$. Combined treatment reduces potentially the risk of disease recurrence and intraperitoneal seeding of infection that may develop via cyst rupture and spillage. Additionally, praziquantel may prevent the vesicular development of protoscoleces and inhibit the formation of secondary cysts. Combination therapy increases levels of albendazole sulphoxide (the active metabolite of albendazole) both in serum and in cyst fluid compared with levels in patients received only albendazole [14]. Praziquantel has been given at a dose of $40 \mathrm{mg} / \mathrm{kg}$ in different regimens for each patient (daily, weekly, fortnightly or monthly) with standard courses of albendazole for between 2 and 3 months. At present, there is scarce evidence supporting a recommendation for the routine use of praziquantel in prolonged chemotherapy for established CE where surgery is not indicated or in severe disseminated disease. This treatment and dosage regimen require evaluation. Further randomized controlled studies are required to determine whether there are significant advantages of combination therapy with albendazole and praziquantel to clarify treatment recommendations. Finally, there are few medical therapeutic options available for $\mathrm{CE}$. As there is some evidence of usefulness of praziquantel in this disease, potential benefits should be explore.

\section{Limitations}

One of the limitations of this study was the calculation of overall effects in the meta-analysis sections due to the scarcity of data. Some authors argue that, since clinical and methodological diversity always occurs in meta-analyses, a good statistical combination of studies is always difficult $[51,52]$. Nevertheless, a qualitative review and a meta-analysis are better than a lack of information. The authors used forest plots to interpret the results of the meta-analyses, which is an accepted methodology. However, when there are few studies, these plots and their associated tests of significance are not very robust, and more studies are necessary to obtain conclusive evidence.

Risks of bias (methodological and clinical) may have a bearing on the results of our qualitative review and meta-analysis. The overall effect of meta-analysis may be affected by publication bias, overestimating the efficacy of treatment, since studies with statistically significant results are more likely to be published than those with non-significant differences. Funnel plots visually check the possible existence of publication bias, but unfortunately, this type of analysis cannot be used when the number of included studies is scarce, as it was the case here.

Despite these limitations, this systematic review and meta-analysis seeks to synthesize the large volume of information available up to date related to medical treatment of CE to help make decisions on evidence-based medicine in daily clinical practice.

\section{Conclusions}

Does our study provide sufficient evidence to influence decisions for the treatment of CE?

In the opinion of the authors, this analysis of the literature suggests the following claims: i) pharmacological treatment improves results in patients with $\mathrm{CE}$ who will undergo surgical treatment; ii) for now, albendazole chemotherapy is the primary medical treatment to consider in the medical management of $\mathrm{CE}$; and iii) treatment with albendazole plus praziquantel shows higher scolicidal activity and a greater number of cysts cured or improved compared to albendazole alone. 


\section{Additional file}

Additional file 1: Search strategy in database. (DOCX $15 \mathrm{~kb}$ )

\section{Abbreviations}

CE: Cystic echinococcosis; CONSORT: Consolidated standards of reporting trials; OCEBM: Oxford centre for evidence-based medicine; PAIR: Puncture, Aspiration, Injection of protoscolicidal agent and Reaspiration; PRISMA: Preferred reporting items for systematic reviews and meta-analyses; WHO: World Health Organization

\section{Acknowledgements}

To Luis Perez del Villar, who started this work with us and could not see it finished.

\section{Funding}

This work was supported by the Health Research Projects: Technological Development Project in Health [Grant number DTS16/00207] and Health Research Project [Grant number PI16/ 01784] of funding institution Instituto de Salud Carlos III and the Network Biomedical Research on Tropical Diseases (RICET in Spanish) RD12/0018/0001, supported by the European Regional Development Fund (FEDER) from the European Commission. Moreover, financial regional/local support came from Proyectos Integrados IBSAL [IBY15/00003; Salamanca, Spain] and CIETUS-University of Salamanca.

\section{Availability of data and materials}

All data generated or analysed during this study are included in this published article [and its supplementary information files].

\section{Authors' contributions}

WT, MAS, MBG, AM, JPL: study design and mayor contributiong to writting; MAS, ALB, ARA, FJB: analysis and interpretation of data. ACP, JLMB, MC: Study implementation and writting. All authors read and approved final versión

\section{Ethics approval and consent to participate}

Not applicable.

\section{Consent for publication}

Not applicable.

\section{Competing interests}

The authors declare that they have no competing interests.

\section{Publisher's Note}

Springer Nature remains neutral with regard to jurisdictional claims in published maps and institutional affiliations.

\footnotetext{
Author details

${ }^{1}$ Servicio de Dermatologia, Complejo Asistencial Universitario de Salamanca (CAUSA), Universidad de Salamanca, Paseo San Vicente 58-182, 37007 Salamanca, Spain. ${ }^{2}$ Instituto de investigación Biomédica de Salamanca (IBSAL), Universidad de Salamanca, Paseo San Vicente 58-182, 37007 Salamanca, Spain. ${ }^{3}$ Centro de Investigación de Enfermedades Tropicales de la Universidad de Salamanca (CIETUS), Universidad de Salamanca, Paseo San Vicente 58-182, 37007 Salamanca, Spain. ${ }^{4}$ Área de Medicina Preventiva y Salud Pública, IBSAL, Universidad de Salamanca, C/Donantes de Sangre s/n. Campus Unamuno, 37007 Salamanca, Spain. ${ }^{5}$ Servicio de Medicina Interna, CAUSA, Paseo San Vicente 58-182, 37007 Salamanca, Spain. ${ }^{6}$ CIETUS, Paseo San Vicente 58-182, 37007 Salamanca, Spain. ${ }^{7}$ Servicio de Medicina Interna, CAUSA, Universidad de Salamanca, Paseo San Vicente 58-182, 37007 Salamanca, Spain. ${ }^{8}$ Departamento Química-Física, Facultad de Farmacia, Universidad de Salamanca, C/Donantes de Sangre s/n. Campus Unamuno, 37007 Salamanca, Spain. ' 2 Laboratorio de Inmunología Parasitaria y Molecular, CIETUS, IBSAL, Facultad de Farmacia, Universidad de Salamanca, C/Donantes de Sangre s/n. Campus Unamuno, 37007 Salamanca, Spain. ${ }^{10}$ Servicio de Microbiología, CAUSA, Universidad de Salamanca, Paseo San Vicente 58-182, 37007 Salamanca, Spain. ${ }^{11}$ Servicio de Medicina Interna, Hospital Marqués de Valdecilla, Avenida Valdecilla 25, 39008 Santander, Cantabria, Spain. ${ }^{12}$ Servicio de Medicina Interna, Sección de Enfermedades Infecciosas, CAUSA,
}

Universidad de Salamanca, Paseo San Vicente 58-182, 37007 Salamanca, Spain.

Received: 26 July 2017 Accepted: 21 June 2018

Published online: 05 July 2018

\section{References}

1. Budke CM, Deplazes P, Torgerson PR. Global socioeconomic impact of cystic echinococcosis. Emerg Infect Dis. 2006;12:296-303. https://doi.org/10.3201/ eid1202.050499.

2. Hotez PJ, Molyneux DH, Fenwick A, Kumaresan J, Sachs SE, Sachs JD, et al. Control of neglected tropical diseases. N Engl J Med. 2007;357:1018-27. https://doi.org/10.1056/NEJMra064142.

3. Lopez-Bernus A, Belhassen Garcia M, Alonso-Sardón M, Carpio-Perez A, Velasco-Tirado V, Romero-Alegria A, et al. Surveillance of human echinococcosis in Castilla-Leon (Spain) between 2000-2012. PLoS Negl Trop Dis. 2015;9:e0004154. https://doi.org/10.1371/journal.pntd.0004154. Torgerson PR, editor. Public Library of Science

4. Junghanss T, da Silva AM, Horton J, Chiodini PL, Brunetti E. Clinical management of cystic echinococcosis: state of the art, problems, and perspectives. Am J Trop Med Hyg. 2008;79:301-11.

5. Vuitton DA. Benzimidazoles for the treatment of cystic and alveolar echinococcosis: what is the consensus? Expert Rev Anti-Infect Ther. 2009;7:145-9.

6. Stojkovic M, Zwahlen M, Teggi A, Vutova K, Cretu CM, Virdone $R$, et al. Treatment response of cystic echinococcosis to benzimidazoles: a systematic review. PLoS Negl Trop Dis. 2009:3:e524. https://doi.org/10.1371/ journal.pntd.0000524. Carabin H, editor. Public Library of Science

7. Alvela-Suárez L, Velasco-Tirado V, Belhassen-Garcia M, Novo-Veleiro I, Pardo-Lledías J, Romero-Alegría A, Pérez del Villar L, Valverde-Merino MP, Cordero-Sánchez M. Safety of the combined use of praziquantel and albendazole in the treatment of human hydatid disease. Am J Trop Med Hyg. 2014;90:819-22. https://doi.org/10.4269/ajtmh.13-0059.

8. Mohamed AE, Yasawy MI, al MA K. Combined albendazole and praziquantel versus albendazole alone in the treatment of hydatid disease. Hepato-Gastroenterology. 1998:45:1690-4

9. Cobo F, Yarnoz C, Sesma B, Fraile P, Aizcorbe M, Trujillo R, et al. Albendazole plus praziquantel versus albendazole alone as a pre-operative treatment in intra-abdominal hydatisosis caused by Echinococcus granulosus. Trop Med Int Health. 1998:3:462-6.

10. Pérez Molina JA, Díaz-Menéndez M, Gallego Jl, Norman F, Monge-Maillo B, Ayala AP, et al. Evaluation of nitazoxanide for the treatment of disseminated cystic echinococcosis: report of five cases and literature review. Am J Trop Med Hyg. 2011;84:351-6. https://doi.org/10.4269/ajtmh.2011.10-0513. American Society of Tropical Medicine and Hygiene

11. OCEBM Levels of evidence - CEBM. 2016.

12. Liberati A, Altman DG, Tetzlaff J, Mulrow C, Gøtzsche PC, loannidis JPA, et al. The PRISMA statement for reporting systematic reviews and meta-analyses of studies that evaluate health care interventions: explanation and elaboration. 2009:e1000100. https://doi.org/10.1371/journal.pmed.1000100.

13. Aktan AO, Yalin R. Preoperative albendazole treatment for liver hydatid disease decreases the viability of the cyst. Eur J Gastroenterol Hepatol. 1996;8:877-9.

14. Bygott JM, Chiodini PL. Praziquantel: neglected drug? Ineffective treatment? Or therapeutic choice in cystic hydatid disease? Acta Trop. 2009;111:95-101. https://doi.org/10.1016/j.actatropica.2009.04.006.

15. Di Matteo G, Bove A, Chiarini S, Capuano LG, De Antoni E, Lanzi G, et al. Hepatic echinococcus disease: our experience over 22 years. HepatoGastroenterology. 1996:43:1562-5.

16. Doğru D, Kiper N, Ozçelik U, Yalçin E, Göçmen A. Medical treatment of pulmonary hydatid disease: for which child? Parasitol Int. 2005:54:135-8. https://doi.org/10.1016/j.parint.2005.02.003.

17. el-Mufti M, Kamag A, Ibrahim H, Taktuk S, Swaisi I, Zaidan A, et al. Albendazole therapy of hydatid disease: 2-year follow-up of 40 cases. Ann Trop Med Parasitol. 1993:87:241-6.

18. Ghoshal AG, Sarkar S, Saha K, Sarkar U, Kundu S, Chatterjee S, et al. Hydatid lung disease: an analysis of five years cumulative data from Kolkata. J Assoc Physicians India. 2012:60:12-6.

19. Horton RJ. Albendazole in treatment of human cystic echinococcosis: 12 years of experience. Acta Trop. 1997:64:79-93.

20. Kern P. Echinococcus granulosus infection: clinical presentation, medical treatment and outcome. Langenbecks Arch Surg. 2003:388:413-20. https:// doi.org/10.1007/s00423-003-0418-y. Springer-Verlag 
21. Larrieu E, Del Carpio M, Salvitti JC, Mercapide C, Sustersic J, Panomarenko H, et al. Ultrasonographic diagnosis and medical treatment of human cystic echinococcosis in asymptomatic school age carriers: 5 years of follow-up. Acta Trop. 2004;91:5-13. https://doi.org/10.1016/j.actatropica.2004.02.006.

22. Li T, Ito A, Pengcuo R, Sako Y, Chen X, Qiu D, et al. Post-treatment follow-up study of abdominal cystic echinococcosis in tibetan communities of Northwest Sichuan Province, China. PLoS Negl Trop Dis. 2011;5:e1364. https://doi.org/10.1371/journal.pntd.0001364. Garcia HH, editor. Public Library of Science

23. Mikić D, Trnjak Z, Bojić I, Begović V, Stanković N, Kupresanić S, et al. Personal experience in the diagnosis and treatment of hepatic echinococcosis. Vojnosanit Pregl. 1998:55:489-99.

24. Nahmias J, Goldsmith R, Soibelman M, el-On J. Three- to 7-year follow-up after albendazole treatment of 68 patients with cystic echinococcosis (hydatid disease). Ann Trop Med Parasitol. 1994;88:295-304.

25. Redzić B, Radulović S, Stanković N, Redzić-Rosko Z. Praziquantel in the treatment of human echinococcosis. Vojnosanit Pregl. 1995;52:155-9.

26. Salinas JL, Vildozola Gonzales H, Astuvilca J, Arce-Villavicencio Y, CarbajalGonzalez D, Talledo L, et al. Long-term albendazole effectiveness for hepatic cystic echinococcosis. Am J Trop Med Hyg. 2011;85:1075-9. https://doi.org/ 10.4269/ajtmh.2011.11-0382. American Society of Tropical Medicine and Hygiene

27. Stamatakos M, Sargedi C, Stefanaki C, Safioleas C, Matthaiopoulou I, Safioleas M. Anthelminthic treatment: an adjuvant therapeutic strategy against Echinococcus granulosus. Parasitol Int. 2009:58:115-20. https://doi. org/10.1016/j.parint.2009.01.002.

28. Tarnovetchi C, Aprodu GS, Oancea M. Diagnosis and treatment of abdominal hydatid cysts in children. A multicentric study. Rev Med Chir Soc Med Nat lasi. 2010;114:1087-91.

29. Todorov T, Vutova K, Mechkov G, Georgiev P, Petkov D, Tonchev Z, et al Chemotherapy of human cystic echinococcosis: comparative efficacy of mebendazole and albendazole. Ann Trop Med Parasitol. 1992;86:59-66.

30. Yasawy MI, al MA K, Mohamed AR. Combination of praziquantel and albendazole in the treatment of hydatid disease. Trop Med Parasitol. 1993;44:192-4.

31. Yasawy MI, Alkarawi MA, Mohammed AR. Prospects in medical management of Echinococcus granulosus. Hepato-Gastroenterology. 2001;48:1467-70.

32. Yilmaz Y, Kösem M, Ceylan K, Köseoglu B, Yalçinkaya I, Arslan H, et al. Our experience in eight cases with urinary hydatid disease: a series of 372 cases held in nine different clinics. Int J Urol. 2006;13:1162-5. https://doi.org/10. 1111/j.1442-2042.2006.01482.x.

33. Bildik N, Cevik A, Altintaş M, Ekinci H, Canberk M, Gülmen M. Efficacy of preoperative albendazole use according to months in hydatid cyst of the liver. J Clin Gastroenterol. 2007;41:312-6. https://doi.org/10.1097/01.mcg. 0000225572.50514.e6.

34. Davis A, Pawlowski ZS, Dixon H. Multicentre clinical trials of benzimidazolecarbamates in human echinococcosis. Bull World Health Organ. 1986;64:383-8. World Health Organization

35. Davis A, Dixon H, Pawlowski ZS. Multicentre clinical trials of benzimidazolecarbamates in human cystic echinococcosis (phase 2). Bull World Health Organ. 1989;67:503-8. World Health Organization

36. Franchi C, Di Vico B, Teggi A. Long-term evaluation of patients with hydatidosis treated with benzimidazole carbamates. Clin Infect Dis. 1999;29: 304-9. https://doi.org/10.1086/520205.

37. Gil-Grande LA, Rodriguez-Caabeiro F, Prieto JG, Sánchez-Ruano JJ, Brasa C, Aguilar $L$, et al. Randomised controlled trial of efficacy of albendazole in intra-abdominal hydatid disease. Lancet. 1993;342:1269-72.

38. Keshmiri M, Baharvahdat $\mathrm{H}$, Fattahi SH, Davachi B, Dabiri RH, Baradaran H, et al. A placebo controlled study of albendazole in the treatment of pulmonary echinococcosis. Eur Respir J. 1999;14:503-7.

39. Keshmiri M, Baharvahdat H, Fattahi SH, Davachi B, Dabiri RH, Baradaran H, et al. Albendazole versus placebo in treatment of echinococcosis. Trans R Soc Trop Med Hyg. 2001;95:190-4.

40. Khuroo MS, Dar MY, Yattoo GN, Zargar SA, Javaid G, Khan BA, et al. Percutaneous drainage versus albendazole therapy in hepatic hydatidosis: a prospective, randomized study. Gastroenterology. 1993;104:1452-9.

41. Shams-UI-Bari ASH, Malik AA, Khaja AR, Dass TA, Naikoo ZA. Role of albendazole in the management of hydatid cyst liver. Saudi J Gastroenterol. 2011;17:343-7. https://doi.org/10.4103/1319-3767.84493.

42. Brunetti E, Kern P, Vuitton DA. Writing panel for the WHO-IWGE. Expert consensus for the diagnosis and treatment of cystic and alveolar echinococcosis in humans. Acta Trop. 2010;114:1-16. https://doi.org/10. 1016/j.actatropica.2009.11.001.

43. De Rosa F, Teggi A. Treatment of Echinococcus granulosus hydatid disease with albendazole. Ann Trop Med Parasitol. 1990;84:467-72.

44. Prousalidis J, Kosmidis C, Anthimidis G, Kapoutzis K, Karamanlis E, Fachantidis E. Postoperative recurrence of cystic hydatidosis. Can J Surg. 2012;55:15-20. https://doi.org/10.1503/cjs.013010.

45. Piccoli L, Tamarozzi F, Cattaneo F, Mariconti M, Filice C, Bruno A, et al. Long-term sonographic and serological follow-up of inactive echinococcal cysts of the liver: hints for a "watch-and-wait" approach. PLoS Negl Trop Dis. 2014;8:e3057. https://doi.org/10.1371/journal.pntd.0003057. Lustigman S, editor. Public Library of Science

46. El-On J. Benzimidazole treatment of cystic echinococcosis. Acta Trop. 2003; 85:243-52.

47. Smego RA Jr, Sebanego P. Treatment options for hepatic cystic echinococcosis. Int J Infect Dis. 2005;9:69-76.

48. Smith AL, Rego LP, Williams R. Albendazole monitoring. Am J Health Syst Pharm. 1997:54:319-20.

49. Kumar A, Lal BK, Chattopadhyay TK. Hydatid disease of the liver-non surgical options. J Assoc Physicians India. 1993;41:437-8. 443

50. Salto E, Juárez E, Roiz MP, Abad J. Combined chemotherapy (mebendazole plus praziquantel) in patients with hydatidosis. Enferm Infecc Microbiol Clin. 1991;9:527-9.

51. Higgins JPT, Thompson SG. Quantifying heterogeneity in a meta-analysis. Stat Med. 2002;21:1539-58. https://doi.org/10.1002/sim.1186. John Wiley \& Sons, Ltd

52. Higgins JPT, Thompson SG, Deeks JJ, Altman DG. Measuring inconsistency in meta-analyses. BMJ. 2003;327:557-60. https://doi.org/10.1136/bmj.327. 7414.557. British Medical Journal Publishing Group

\section{Ready to submit your research? Choose BMC and benefit from:}

- fast, convenient online submission

- thorough peer review by experienced researchers in your field

- rapid publication on acceptance

- support for research data, including large and complex data types

- gold Open Access which fosters wider collaboration and increased citations

- maximum visibility for your research: over $100 \mathrm{M}$ website views per year

At BMC, research is always in progress.

Learn more biomedcentral.com/submissions 